\title{
Demographic and Clinical profile of 190 COVID- 19 Patients in a Tertiary Care Private Hospital of Dhaka, Bangladesh: An Observational Study
}

\author{
Homayara Tahseen Hossain ${ }^{1}$, Tasmina Chowdhury ${ }^{2}$, Maksudul Islam Majumder ${ }^{3}$,Arfa Rahman Ava ${ }^{4}$, Quazi \\ Audry Arafat Rahman' ${ }^{5}$ Md. Zahiruddin ${ }^{6}$,HAM Nazmul Ahasan7, Quazi Tarikul Islam ${ }^{8}$
}

\begin{abstract}
:
From late December'19 till the end of August 2020, in this nine months period, world has lost more than eight hundred thousands people due to COVID-19 pandemic. Clinical data on COVID-19 in Bangladesh is less. The objective of our study was to evaluate demographic and clinical profile with in a defined period among COVID-19 Bangladeshi Patients in a Tertiary Care Private Medical College Hospital of Dhaka. We conducted a retrospective descriptive study on epidemiological \& clinical profile along with short term treatment outcomes of 190 COVID-19 patients from COVID dedicated unit of Popular Medical College Hospital (PMCH) during the period of I8th June to 22nd August 2020 (2 months) with a pre-determined case record form (CRF).Among this 190 patients, mean age was found to be 53 years. Highest percentage of patients (44\%) belonged to 4I-60 years of age. Regarding gender distribution, two-third patients were male $(65 \%)$ \& one-third patients were female $(35 \%)$. The predominant symptoms of our enrolled patients were fever (88\%), cough (81\%), dyspnoea (58\%) \& fatigue( 50\%). Around half of the patients had been suffering from Hypertension (54\%) and Diabetes (47\%). Almost half of our patients belonged to moderate severity (48\%). The duration of Hospital stay was from I-36 days, mean was 7 days. There was significant difference for severe and non-severe cases ( $p$ value 0.01 ).
\end{abstract}

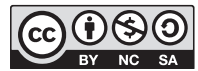

DOI: https://doi.org// 0.3329/jom.v2 Ii2.502 I0

Copyright: (C) 2020 Hossain HT et al. This is an open access article published under the Creative Commons Attribution-NonCommercial-NoDerivatives 4.0 International License, which permits use, distribution and reproduction in any medium, provided the original work is properly cited, is not changed in any way and it is not used for commercial purposes.

Received: 10 August 2020;

Accepted: 25 August 2020

\section{Introduction:}

From late December'19 till the end of August 2020, in this nine months period, more than 23 million people are affected globally with more than eight hundred thousands death due to COVID-19 pandemic ${ }^{1}$. The whole world is fighting against this invisible enemy. People are trying hard to adopt with this new normal life. Global economy is facing huge challenge. We still do not know when this devastating situation will come to an end; when we can breathe in fresh air, without wearing masks.

1. Associate Professor of Medicine, Popular Medical College

2. Registrar of Medicine, Popular Medical College

3. Registrar of Medicine, Popular Medical College

4. Assistant.Registrar of Medicine, Popular Medical College

5. Assistant, Registrar of Medicine, Popular Medical College

6. Professor of Medicine, Popular Medical College

7. Professor of Medicine, Popular Medical College

8. Professor of Medicine, Popular Medical College

Address of correspondence: Dr. Homayra Tahseen Hossain, FCPS, MRCP, Associate Professor of Medicine, Popular Medical College Hospital, Dhaka. Email: homayra.tahseen@gmail.com
As this is a novel coronavirus, still evolving, we are learning new information every day. Scientific research is going on throughout the world to know more about this virus, so that we can combat against it. Though severe acute respiratory illness with fever and respiratory symptoms comprise the main clinical presentations ${ }^{2}$, but we must keep in mind the atypical presentations, so that no case will remain undiagnosed. Understanding regional features are always important. There are few published studies on COVID-19 patients from Government Hospitals. So, we conducted this descriptive study on 190 COVID-19 cases from COVID dedicated unit of a tertiary care Private Medical College Hospital to give a highlight on the epidemiological \& clinical profile in our private hospital setting.

\section{Methodology:}

a) Study Design:

We conducted a retrospective descriptive study on epidemiological \& clinical profile along with short term treatment outcomes of COVID-19 patients from COVID dedicated unit of Popular Medical College Hospital (PMCH) during the period of $18^{\text {th }}$ June to $22^{\text {nd }}$ August 2020 ( 2 months). 


\section{b) Study Population:}

We selected consecutive 190 patients from COVID dedicated isolation wards/ cabins of Popular Medical College Hospital. Patients were diagnosed COVID-19 case either by real-time polymerase chain reaction (RT-PCR) positivity or by clinical features along with typical HRCT chest findings. The patients who were critically ill and admitted directly in ICU were not included in our study. The study was approved by Institutional Ethical Committee and written informed consent was obtained from patients involved before enrolment.

\section{c) Data Collection:}

A team of doctors who had been treating these patients extracted the medical records from direct interviewing the patients/ attendants after taking the written informed consent $\&$ also from the hospital records. All the data were included in a previously prepared Case Record Form, giving particular ID number to each patient.

\section{d) Variables:}

The data included contact history, demographic information and clinical presentation including symptoms on admission and co-morbidities, laboratory investigation reports including chest imaging, treatment programs, and clinical outcomes along with duration of hospital stay.

We clinically classified the patients' severity according to the clinical criteria of our national guideline (version 7.0$)^{3}$

\begin{tabular}{ll}
\hline $\begin{array}{l}\text { Grading of } \\
\text { severity }\end{array}$ & \multicolumn{1}{c}{ Criteria } \\
\hline Mild & $\begin{array}{l}\text { The clinical symptoms are mild, and there } \\
\text { is no sign of pneumonia on imaging. }\end{array}$ \\
Moderate & $\begin{array}{l}\text { Fever and respiratory symptoms with } \\
\text { radiological findings of pneumonia. } \\
\text { Respiratory distress with }<30 \text { breaths } / \text { min, } \\
\text { Pulse oxymetry showing saturation }>93 \% \\
\text { at ambient air }\end{array}$
\end{tabular}

Severe Cases meeting any of the following criteria:Respiratory distress (g"30 breaths/min);Finger oxygen saturationd"93\% at rest;Arterial partial pressure of oxygen $(\mathrm{PaO} 2) /$ fraction of inspired oxygen (FiO2) f'300mmHg $(\operatorname{lmmHg}=0.133 \mathrm{kPa})$

Critical Cases meeting any of the following criteria:Respiratory failure and requiring mechanical ventilation- Shock.- With other organ failure that requires ICU care.

e) Laboratory tests:

Nasopharyngeal swab specimens from the upper respiratory tract that were obtained from all patients at admission and
2019-nCoV was confirmed by real-time RT-PCR. All patients were given chest $\mathrm{X}$-rays on admission. HRCT chest was done in selected patients. In addition, complete panel of routine laboratory tests, including complete blood count, blood biochemistry, CRP, D-dimer, Ferritin and Procalcitonin was also done according to clinical requirement.

Normal or low TC of WBC, Lymphopenia, High CRP, Low Procalcitonin associated with bilateral pneumonia in Chest $\mathrm{X}$-ray or GGO in CT scan of Chest: Diagnosis is COVID-19 during this epidemic ${ }^{3}$ regardless of RT-PCR positivity .

\section{f) Statistical analysis:}

All statistical analysis was carried out using the STATA version 14. Descriptive and inferential statistics were used in this analysis. Frequency and percentages are presented for the categorical variables such as fever, cough \& other symptoms and mean \pm standard deviation and median are presented for the continuous variables like age, duration of Hospital stay. t-test \& chi-square test was done to assess whether there was any co-relation of severity with Age, duration of hospital stay \& gender.

\section{Results:}

190 COVID-19 patients( Both RT-PCR positive\& negative) from COVID dedicated unit of Popular Medical College Hospital (PMCH) were enrolled in our study during a period of 2 months(18th June to 22nd August 2020), after Popular Medical College officially started treating COVID-19 patients among the Private hospitals in Dhaka.

\section{a) Demographic Characteristics:}

The age range of our patients was 12- 86 years. Mean age was 53 years. Highest percentage of patients (44\%) belonged to 41-60 years of age (table-01). Regarding gender distribution, two-third patients were male $(65 \%)(n-123) \&$ one-third patients were female (35\%) (n- 67) (Table -01)

Table-I: Distribution of patients according to Age

\begin{tabular}{lcc}
\hline Age (Years) & $\mathrm{n}$ & $\%$ \\
\hline $0-20$ & 02 & 1.05 \\
$21-40$ & 43 & 22.63 \\
$41-60$ & 84 & 44.21 \\
$61 \&$ above & 61 & 32.11 \\
\hline Total & 190 & 100 \\
\hline
\end{tabular}




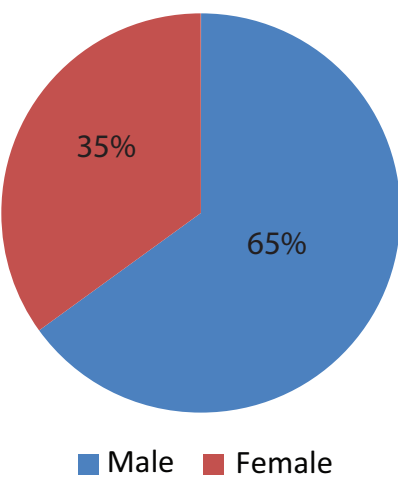

Fig.-1: Gender distribution

\section{b) Clinical Characteristics \& Co-morbidites:}

Regarding symptoms, fever $(88 \%)$ with respiratory symptoms like cough( $81 \%) \&$ dyspnea (58\%) topped the list, followed by fatigue ( 50\%)( Table-02). Anosmia \& altered taste sensation were 2 specific symptoms of COVID-19, which was present in $21 \%$ \& $14 \%$ of patients respectively. Other than respiratory symptoms, patients also present with gastro-intestinal \& neurological symptoms. Regarding comorbidities, around half of the patients had been suffering from Hypertension (54\%) and Diabetes (47\%), other less common associated co-morbidities \& risk factors are shown in Table-03.

Table-II: Symptoms

\begin{tabular}{lcccc}
\hline Symptoms & Present (Number) & Present (\%) & Absent (Number) & Absent (\%) \\
\hline Fever & 167 & 87.9 & 23 & 12.1 \\
Cough & 153 & 80.5 & 37 & 19.5 \\
Dyspnea & 111 & 58.4 & 79 & 41.6 \\
Fatigue & 94 & 49.5 & 96 & 50.5 \\
Anosmia & 40 & 21.1 & 150 & 78.9 \\
Altered Sense of Taste & 27 & 14.2 & 163 & 85.8 \\
Sore Throat & 59 & 31.1 & 131 & 68.9 \\
Anorexia & 38 & 20 & 152 & 80 \\
Diarrhoea & 23 & 12.1 & 167 & 87.9 \\
Headache & 11.6 & 168 & 88.4 \\
Vomiting & 12 & 6.3 & 178 & 93.7 \\
Chest Pain & 08 & 4.2 & 182 & 95.8 \\
Nasal Congestion & 08 & 4.2 & 182 & 95.8 \\
Confusion & 05 & 2.6 & 185 & 97.4 \\
Dizziness & 04 & 186 & 97.9 \\
Conjunctivitis & 01 & 0.5 & 189 & 99.5 \\
\hline
\end{tabular}

Table-03: Co-morbidities \& Risk Factors

\begin{tabular}{llcccc}
\hline & Co-morbidities & $\begin{array}{c}\text { Present } \\
\text { (Number) }\end{array}$ & $\begin{array}{c}\text { Present } \\
(\%)\end{array}$ & $\begin{array}{c}\text { Absent } \\
\text { (Number) }\end{array}$ & $\begin{array}{c}\text { Absent } \\
(\%)\end{array}$ \\
\hline \& Risk Factors & 103 & 54.2 & 87 & 45.8 \\
& HTN & 90 & 47.4 & 100 & 52.6 \\
& DM & 27 & 14.2 & 163 & 85.8 \\
& Br. Asthma & 11 & 5.8 & 179 & 94.2 \\
& CHD & 8 & 4.2 & 182 & 95.8 \\
& CVD & 2 & 1.1 & 188 & 98.9 \\
& COPD & 11 & 5.8 & 179 & 94.2 \\
& CKD & 37 & 19.5 & 153 & 80.5 \\
& Smoking & 01 & 0.5 & 189 & 99.5 \\
& Obesity & 01 & 0.5 & 189 & 99.5 \\
& Chemotherapy & 01 & 0.5 & 189 & 99.5 \\
\hline
\end{tabular}




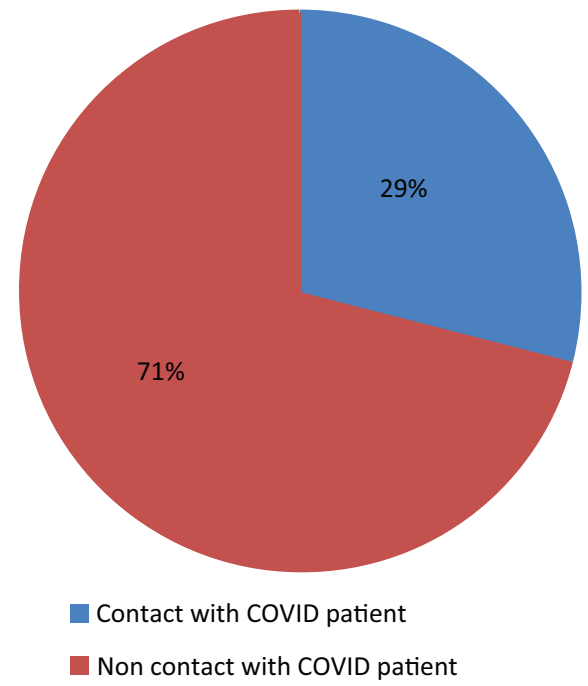

Fig.-2: History of Contact with COVID patient

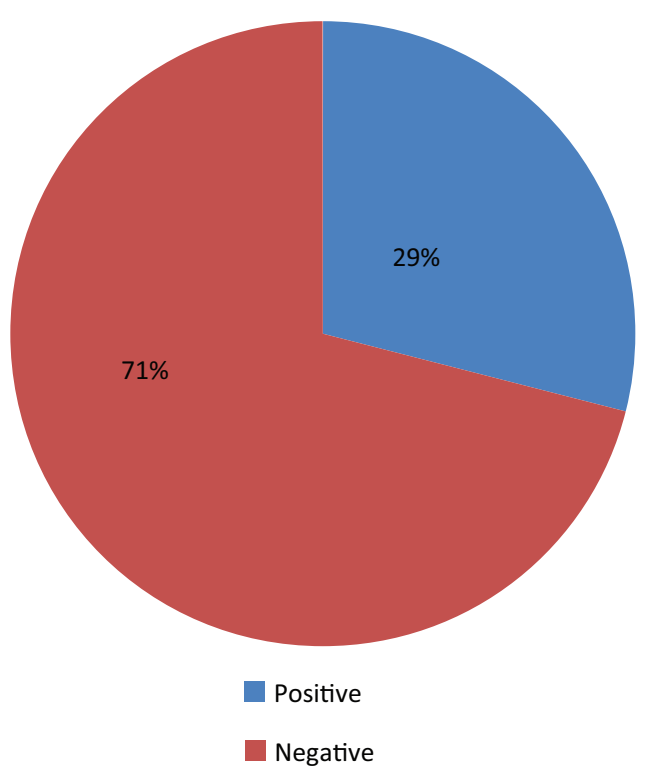

Fig.-3: RT-PCR positivity

\section{d) Grading of Severity:}

Almost half of our patients belonged to moderate severity $(48 \%)$, mild was (29\%), severe $(22 \%)$ \& critical only $(01 \%)$ (Figure-04).

\section{e) Treatment Outcome \& Duration of Hospital Stay:}

We could discharge almost $80 \%$ of our patients with $08 \%$ referred for Intensive care $\&$ only 03 deaths (Table-04). The duration of Hospital stay was from 1-36 days, mean was 7 days.

\section{c) Contact History \& Status of RT-PCR test :}

Only less than half of the patients $(47 \%)$ could mention history of contact with COVID patients (Figure-02), which indicate community transmission. We did RT-PCR of nasopharyngeal swab of all patients, $71 \%$ (n-135) came positive (Figure-03).

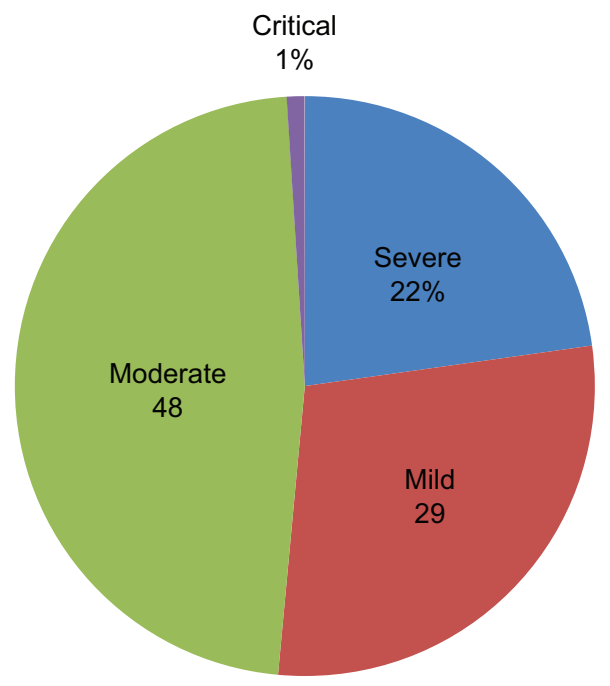

Fig.-04: Grading of severity

Table-IV

Treatment Outcome

\begin{tabular}{lcc}
\hline Outcome & $\begin{array}{c}\text { Total Number } \\
(\mathrm{n})\end{array}$ & $\begin{array}{c}\text { Percentage } \\
(\%)\end{array}$ \\
\hline Discharged with improvement & 151 & 79.5 \\
Ongoing Treatment in Hospital & 21 & 11 \\
Referred to ICU/ HDU & 15 & 7.9 \\
Death & 03 & 1.6 \\
\hline Total & 190 & 100 \\
\hline
\end{tabular}

\section{g) Association of severity :}

It was statistically analyzed \& found that age $\&$ sex are not significantly different for severe and non-severe cases $(\mathrm{p}>0.05)$. But duration of hospital stay is significantly different for severe and non-severe cases $(p<0.05)$. The severely sick patients required longer duration of hospitalization (Table-05). 
Table-V: Association of severity with Age, duration of hospital stay \& gender:

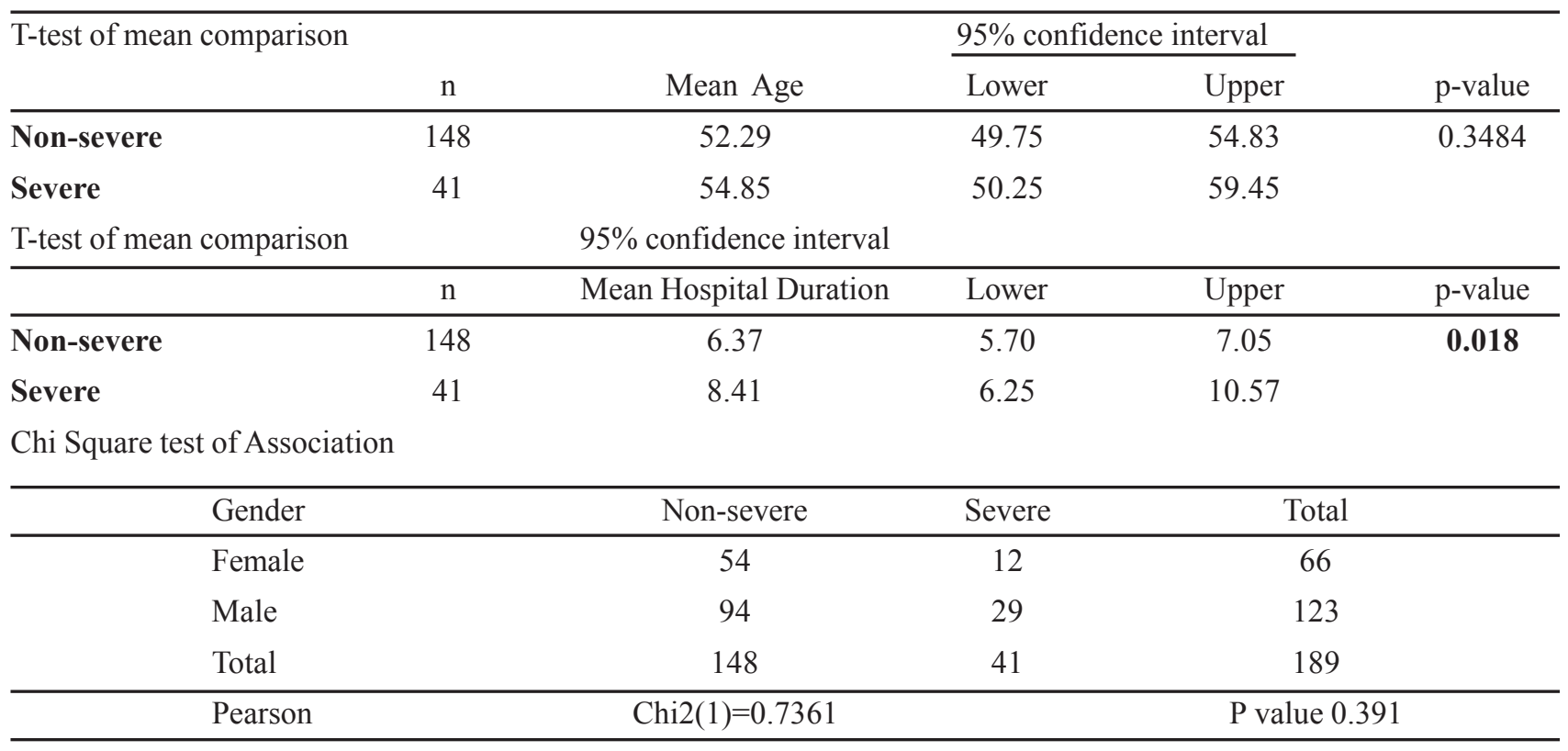

\section{Discussions:}

To our knowledge, this observational study report is the largest case study to date of COVID-19 patients in a Private Hospital of Dhaka recruiting 190 cases on the basis of clinical context with typical chest imaging with or without RT-PCR positivity.

In our study population, mean age was 53 years, which is quite similar with the findings of other studies : 55.5 years Chen et $\mathrm{al}^{4}, 51$ years Chung et $\mathrm{al}^{5}, 49$ years Huang et al ${ }^{6}$, $41.7+$ _ 16.3 years Mowla et al ${ }^{7}$.Infection in children was rare, which was consistent with the results of a study performed by Zhonget $\mathrm{al}^{8}$. The presentation of COVID-19 is predominantly mild and asymptomatic in the age group $<14$. Perhaps the ACE2 receptor is not highly expressed in this age group 9 .

We observed greater percentage of male $(65 \%)$ than female(35\%) affected with COVID-19. Similar male preponderance was found in other studies, $73 \%$ of the first reported study of $\mathrm{China}^{4}$ or $63 \%$ of a study in $\mathrm{DMCH}$, Bangladesh ${ }^{7}$.It has been found that more males were infected by SARS-CoV. ${ }^{10,11}$ Current research suggests that ACE2 is the receptor for COVID-19 ${ }^{12}$, and its expression in men is higher than that in women ${ }^{13}$, which may be the reason for the higher proportion of men with severe illness. The reduced susceptibility of females to viral infections could also be due to the protection from $\mathrm{X}$ chromosome and sex hormones ${ }^{14}$.

The symptomatology of COVID-19 was extensively discussed in WHO-China joint report on COVID-19 ( $\mathrm{n}=$
$55,924)^{15}$ Predominant symptoms are pyrexia $85 \%$, cough $67.7 \%$,productive sputum in $33.4 \% \&$ dyspnoea in $18.6 \%{ }^{16}$. This symptomatology is quite similar to our findings: fever $(88 \%)$, cough with or without sputum production $(81 \%)$, although our patients suffered from more dyspnea (58\%).Studies from Europe first urged the international scientific community that the sudden anosmia or ageusia need to be recognized as important symptoms of the COVID-19 infection ${ }^{17}$. In our study, anosmia \& altered taste sensation was present in $21 \%$ \& $14 \%$ of patients respectively. Different from SARS-CoV and MERS-CoV infections, is that very few COVID-19 patients show prominent upper respiratory tract signs and symptoms such as rhinorrhea or sneezing suggesting that the virus might have greater preference for infecting the lower respiratory tract ${ }^{4}$. Only $4.2 \%$ of our study population had nasal congestion. About half of patients infected by COVID-19 had chronic underlying diseases, mainly cardiovascular and cerebrovascular diseases and diabetes ${ }^{18}$; this is similar to our study result : Hypertension (54\%) and Diabetes (47\%).

It is to be noted that, only $47 \%$ of patients could mention history of contact with COVID patients, which indicate there is community transmission \& transmission from asymptomatic carriers. RT-PCR was positive in $71 \%$ patients. A systematic review of the accuracy of covid-19 tests reported false negative rates of between $2 \%$ and $29 \%$ (equating to sensitivity of 71-98\%), based on negative RTPCR tests which were positive on repeat testing. ${ }^{19}$ That is why, for diagnosis of COVID-19, we did not solely depend on Rt-PCR, rather we gave emphasis on clinical back ground , chest imaging findings \& other laboratory markers. 
Mild symptomatic patients usually do not require hospitalization, they can be treated at home with isolation. We did not include critical patients from ICU/ HDU. That is why, majority of our patients belonged to moderate (48\%) grade of severity.

Median hospital stay ranged from 4 to 53 days within China, and 4 to 21 days outside of China, across 45 studies $^{20}$. This is similar with our study, the duration of Hospital stay in our study was from 01-36 days, mean was 7 days. There was significant difference for severe and non-severe cases ( $p$ value 0.01 ). Severely sick patients required longer duration of hospitalization.

\section{Conclusion\& Recommendation:}

This is an early data, showing the epidemiological and clinical profiles of Bangladeshi COVID-19 patients hospitalized at a Private Hospital in Dhaka. We admit that we have some limitations of our study. The study was done in a single center within a very short time frame on a limited number of samples. Asymptomatic patients, patients with mild symptoms at home and severe cases in ICU could not be included in our study. More detailed patient information, particularly regarding clinical outcomes and follow up, was unavailable at the time of analysis, as some patients were referred \& some were still in hospital. So, the outcome of study needs to be further verified by larger sample with multicenter study with extended follow-up. In conclusion, we must give emphasis on early diagnosis, early isolation and early management of all COVID-19 patients to reduce transmission and mortality, thus to save mankind from this invisible enemy.

\section{Acknowledgement:}

We are thankfull to Ms.Aniqa Tasnim Hossain, Research Investigator, icddr,b for analysing the data.

\section{References:}

1. WHO. Situation report coronavirus (COVID-19)- 134. 10:00 CEST, 24 August 2020. https:/www.who.int/emergencies/ diseases/novel-coronavirus-2019/situation-reports

2. Pauline V, Diem LV, Arnaud G, Manuel S, Laurent K, Frederique J. Clinical features of covid-19, The wide array of symptoms has implications for the testing strategy. BMJ $2020 ; 369$.

3. National Guidelines on Clinical Management of Coronavirus disease 2019( COVID-19), Version 7.0 28 May 2020, Disease Control Division, Directorate General of Health Services, Ministry of Health \& Family Welfare, Government of the People's Republic of Bangladesh, Page-18
4. N. Chen, M. Zhou, X. Dong, J. Qu, F. Gong, Y. Han, et al. Epidemiological and clinical characteristics of 99 cases of 2019 novel coronavirus pneumonia in Wuhan, China: a descriptive study Lancet (2020)

5. M. Chung, A. Bernheim, X. Mei, N. Zhang, M. Huang, X. Zeng, et al.CT imaging features of 2019 novel coronavirus (2019-nCoV) Radiology (2020), p. 200230

6. C. Huang, Y. Wang, X. Li, L. Ren, J. Zhao, Y. Hu, et al. Clinical features of patients infected with 2019 novel coronavirus in Wuhan, China Lancet 2020; 395:497-506.

7. SGM Mowla, KAK Azad, A Kabir et al, Clinical and Epidemiological Profile of 100 Confirmed COVID-19 Patients Admitted in Dhaka Medical College Hospital, Dhaka, Bangladesh, Journal of BCPSJune 2020 DOI: 10.3329/jbcps. v38i0.47445

8. Guan W, Ni Z, Hu Y, et al. Clinical characteristics of 2019 novel coronavirus infection in China. medRxiv. 2020

9. Kadhkar P, Kaka N, Baig MN, A Comprehensive Literature Review on the Clinical Presentation, and Management of the Pandemic Coronavirus Disease 2019 (COVID-19), Cureus. 2020 Apr; 12(4): e7560. PMCID: PMC7138423, PMID: 32269893

10. Badawi A, Ryoo SG. Prevalence of comorbidities in the Middle East respiratory syndrome coronavirus (MERS$\mathrm{CoV})$ : a systematic review and meta-analysis. Int J Infect Dis 2016; 49: 129-33.

11. Channappanavar R, Fett C, Mack M, Ten Eyck PP, Meyerholz DK, Perlman S. Sex-based differences in susceptibility to severe acute respiratory syndrome coronavirus infection. J Immunol 2017; 198:4046-53.

12. Zhou, P., Yang, X.-L., Wang, X.-G., Hu, B., Zhang, L., Zhang, W., Shi,Z.-L. (2020). Discovery of a novel coronavirus associated with the recent pneumonia outbreak in humans and its potential bat origin. bioRxiv.

13. Zhao, Y., Zhao, Z., Wang, Y., Zhou, Y., Ma, Y., \& Zuo, W. (2020). Single-cell RNA expression profiling of ACE2, the putative receptor of Wuhan 2019-nCov., bioRxiv.

14. Jaillon S, Berthenet $\mathrm{K}$, Garlanda C Sexual dimorphism in innate immunity Clin Rev Allergy Immunol, 56 (2019), pp. 308-321 Cross Ref View Record in Scopus Google Scholar

15. Report of the WHO-China joint mission on coronavirus disease 2019 (COVID-19) . (2020). Accessed: March 21, 2020: https://www.who.int/docs/default-source/ coronaviruse/whochina-joint-mission-on-covid-19-finalreport.pdf

16. Guan W-j, Ni Z-y, Hu Y, et al.: Clinical characteristics of coronavirus disease 2019 in China . N Engl J Med. 2020, [Published online ahead of print]:10.1056/NEJMoa2002032 
17. Lechien JR, Chiesa-Estomba CM, Siati DR, Horoi M, Bon SDL, Rodriguez A, et al. Olfactory and gustatory dysfunctions as a clinical presentation of mild-to-moderate forms of the coronavirus disease (COVID-19): a multicenter European study [published online ahead of print, $2020 \mathrm{Apr}$ 6]. Eur Arch Otorhinolaryngol. 2020;1 11. doi:10.1007/ s00405-020-05965-1

18. Nanshan C, Min Z, Xuan D et al .Epidemiological and clinical characteristics of 99 cases of 2019 novel coronavirus pneumonia in Wuhan, China: a descriptive study .The Lancet,
Volume 395, Issue 10223, 15-21 February 2020, Pages 507-513

19. Arevalo-Rodriguez I, Buitrago-Garcia D, Simancas-Racines D, et al. False-negative results of initial RT-PCR assays for covid-19: a systematic review. medRxiv 20066787. 2020 $0.1101 / 2020.04 .16 .20066787 \% \mathrm{~J}$

20. Rees E, Nightingale E, Jafari Y et al. COVID-19 length of hospital stay: a systematic review and data synthesis. May 2020 DOI: $10.1101 / 2020.04 .30 .20084780$. 